\title{
Evaluation of in-vitro antibacterial and antifungal activities of crude extracts and solvent fractions of methanol extract of leaves of Ricinus communis Linn (Euphorbiaceae) against selected pathogens
}

\section{Bedaso Kebede}

Addis Ababa University College of Health Sciences

Workineh Shibeshi ( $\nabla$ workineh.shibeshi@aau.edu.et )

Addis Ababa University College of Health Sciences https://orcid.org/0000-0003-3478-6235

\section{Research article}

Keywords: Antibacterial activity, Antifungal activity, Ricinus communis Linn, MIC, MBC

Posted Date: October 26th, 2020

DOI: https://doi.org/10.21203/rs.3.rs-63537/v2

License: (c) (i) This work is licensed under a Creative Commons Attribution 4.0 International License. Read Full License 


\section{Abstract}

Background Impacts of infectious diseases are reduced due to development of antimicrobial agents. However, the effectiveness of the antimicrobial agents is reduced over time because of the emergence of antimicrobial resistance.To overcome these problems scholars have been searching for alternative medicines, particularly focusing on traditionally used medicinal plants. Ricinus communis Linn is used as a traditional treatment for bovine mastitis, wound infection, and other medicinal purposes. Moreover, the antimicrobial activity of Ricinus communis Linn leaf at crude extract level has been confirmed against human originated pathogens in the previous studies. The objective of the present study was to further evaluate the antimicrobial activities of Ricinus communis Linn leaf extracts and fractions. The Ricinus communis Linn leaves were macerated in absolute methanol and acetone solvents. The methanol crude extract was shown best antimicrobial activity and exposed to further fractionation via increasing polarity of solvents (n-hexane, chloroform, ethyl acetate, and aqueous). Test microorganisms included in the study were six laboratory reference bacteria (E. coli, S. aureus, S. agalactiae, K. pneumoniae, P. aeruginosa, and S. Pyogenes), two clinical isolate bacteria (E. coli and S. aureus), and Candida albicans. The agar well diffusion method was employed to determine antimicrobial activity. The minimum inhibitory concentrations (MIC) and minimum bactericidal/fungicidal concentrations (MBC/MFC) were determined through broth microdilution method.

Results The results indicated that the best antimicrobial activity(based on zone of inhibition) for ethyl acetate fraction ranging from $14.67 \mathrm{~mm}$ (clinical $E$. coli) to $20.33 \mathrm{~mm}$ (S. aureus) at $400 \mathrm{mg} / \mathrm{ml}$ however, n-hexane exhibited lowest antimicrobial activity. Among tested fractions, ethyl acetate fraction was produced lowest MIC values ranging from $1.5625 \mathrm{mg} / \mathrm{ml}$ (S. aureus) to $16.67 \mathrm{mg} / \mathrm{ml}$ (Candida albicans). The ethyl acetate fraction showed bactericidal activity against all tested microorganisms.

Conclusion Methanol extract of Ricinus communis Linn leaf exhibited better antimicrobial activity than acetone extract. Hence, ethyl acetate fraction of crude methanol extract exhibited best antimicrobial activity indicating its potential for development of antimicrobial products.

\section{Background}

Infectious diseases are exacerbated due to the existence of zoonotic diseases and antimicrobial resistance [1, 2]. Several surveillances have been conducted on antimicrobial resistance. The augmentations of antimicrobial resistances have harmed both human and animal health, exposing to longer periods of hospitalization, and affect treatment costs $[3,4,5]$. Alternative medicines have been screening from a variety of plants for their pharmacological potential as secondary metabolites are less in drug adverse effects, resistances, and residues [6, $7,8,9]$.

Ricinus communis Linn in Ethiopia is used for the treatment of blackleg and actinomycosis [10], diarrhoea, wound and skin rashes or dermatitis [11,12], and bovine mastitis [13]. The studies are conducted on validation of antimicrobial activity of Ricinus communis Linn leaf crude extracts using different solvents in Pakistan and Ghana, and methanol crude extract was reported to have a promising antimicrobial potential $[14,15]$. Besides, in Ethiopia Ricinus communis Linn leaf has been demonstrated to have antibacterial activity for an organic solvent solution, but the aqueous extract has shown less activity [16]. However, methanol solvent was not used for extraction in Abew et al. [16] study and none has been done on the antimicrobial activities of solvent fractions of Ricinus communis Linn leaf. 
Antimicrobial activities of medicinal plants are not only determined by plant species. There are also other factors such as altitude, temperature, illumination, and moisture. These factors have regulated accumulation and metabolism of secondary metabolites in medicinal plants. Additionally, differences in the location of medicinal plants have contributed to presence of different active ingredients and their concentrations [17]. Therefore, the current study is intended to evaluate antimicrobial activities of methanol and acetone crude extracts, and solvent fractions of methanol extract that exhibited the best antimicrobial activity.

\section{Methods}

\section{Extraction of the plant}

The plant leaves were collected in October, 2019 from Sululta district, surrounding of Addis Ababa, Ethiopia. The specimen was authenticated by a taxonomist at Herbarium of the college of natural and computational sciences, Addis Ababa University, and voucher number (002/BK) was deposited for future reference.

The extraction of leaves was performed according to Ogbiko et al. [18]. The powdered leaves of 200 grams were weighed on an analytical balance (Mettler Toledo, Switzerland) and macerated in $1000 \mathrm{ml}$ of absolute methanol and acetone in Erlenmeyer flask at the ratio of 1:5; after three days extract was collected and marc was remacerated. Collection of the extract was carried out at the interval of three days, so leaves were macerated totally for 9 days with the intermittent shaking on the rotary-shaker (VWR DS-500; The Lab World Group, Boston, MA, USA). The pooled extract was first filtered through sieve mesh then followed by filtration via Whatman no. 1 by using filtration apparatus or unit. A filtrate of extracts was concentrated in a rotary evaporator (Buchii model R-200, Switzerland) at $40^{\circ} \mathrm{C}$ temperature and 40 revolutions per minute (RPM) until solvents were completely removed and solid extracts were formed.

\section{Crude extract solvent fractionation}

The crude methanol extract was subjected to further solvent fractionation by increasing polarity including $\mathrm{n}$ hexane, chloroform, ethyl acetate, and aqueous. Voukeng et al. [19] method was used for solvent fractionation with modification on the concentration of extract residue between fractionation intervals. The methanol crude extract was not completely dissolved in water, therefore, $90 \%$ methanol solvent was used as diluent. The methanol crude extract 60 grams were weighed on an analytical balance and subjected to dissolve completely in $100 \mathrm{ml}$ of $90 \%$ methanol (10 ml water and $90 \mathrm{ml}$ methanol) in the beaker. The completely dissolved $100 \mathrm{ml}$ methanol crude extract was mixed with $100 \mathrm{ml} \mathrm{n}$-hexane for solvent partitioning in separatory funnel having a capacity of $250 \mathrm{ml}$. The mixture in separatory funnel was fixed to the standing stage pole and waited until a clear and separated layer formed between two solvents. Once a clear layer formed, the methanol part was taken first carefully to beaker and n-hexane partition to another container. This procedure was repeated three times, the n-hexane partition was collected together for future concentration. While the remaining crude methanol extract solution was subjected to evaporation in a rotary evaporator at $40^{\circ} \mathrm{C}$ and $40 \mathrm{rpm}$ to remove methanol. Then, $90 \mathrm{ml}$ of water was added to the concentrated crude methanol extract to form a $100 \mathrm{ml}$ aqueous solution. The $100 \mathrm{ml}$ aqueous solution of crude methanol extract was mixed with $100 \mathrm{ml}$ of chloroform in the separatory funnel. The separatory funnel was fixed on the standing stage pole and waited until a clear layer formed between the aqueous solution of crude methanol extract and chloroform. The chloroform portion was held lower layer and collected first in the container and aqueous portion in another container. It was replicated three times and the chloroform portion pooled in the container for later concentration. The remnant aqueous portion of crude methanol extract was concentrated on a 
rotary evaporator to remove the remaining chloroform. The concentrated $100 \mathrm{ml}$ aqueous portion of crude methanol extract was mixed with $100 \mathrm{ml}$ ethyl acetate in the separatory funnel. The separatory funnel was fixed on the standing stage pole and waited till a clear layer appeared between aqueous fraction and ethyl acetate fraction. It was repeated three times, and aqueous fraction and ethyl acetate fraction were collected in different containers. The aqueous fraction was lyophilized by lyophilizer (Operon, Korea vacuum limited, Korea), but n-hexane, chloroform, and ethyl acetate fractions were concentrated in a rotary evaporator.

\section{Preliminary phytochemical screening}

The crude extracts and fractions were screened for phytochemical constituents or secondary metabolites using standard methods. Tannins and cardiac glycosides were screened as described by Ayoola et al.2008(20), steroids and anthraquinones were screened as described by Nwadiaro et al.2015 (21), flavonoids, terpenoids, phenolic compounds were detected as described by Shetty et al.2016(22), while alkaloids were detected as described by Santhi et al.2016(23) .

\section{Test organisms}

Microorganisms selected for the experiment were standard strains including Staphylococcus aureus (ATCC 25923), Streptococcus agalactiae (ATCC 12386), Streptococcus pyogenes (ATCC 19615), Escherichia coli (ATCC 25922), Pseudomonas aeruginosa (ATCC 27853) and Klebsiella pneumoniae (ATCC 700603) brought from Ethiopian Public Health Institute, and clinical isolates Staphylococcus aureus and Escherichia coli obtained from Animal Products, Veterinary Drug and Animal Feed Quality Assessment Centre of Veterinary Drug and Animal Feed Administration and Control Authority, and Candida albicans (ATCC10231) brought from Ethiopian Biodiversity Institute. The gram staining, selective media, haemolysin, and catalase test were conducted to confirm test microorganisms according to $[24,25]$.

\section{Standard drugs}

Gentamicin 10 $\mu \mathrm{g}$ disc was used as positive control against bacteria and brought from Animal Products, Veterinary Drug, and Animal Feed Quality Assessment Centre of Ethiopian Veterinary Drug and Animal Feed Administration and Control Authority. Amphotericin-B 20 $\mathrm{g}$ was used as positive control against fungus and obtained from the Ethiopia Food and Drug Administration and Control Authority. The standard drugs were used based on sensitivity against selected microorganisms and availability in the laboratory.

\section{Antibacterial activity}

The brain heart infusion (BHI) broth was prepared for streptococcal species and nutrient broth for other test bacteria. Overnight cultured 3-5 distinct colonies of bacteria based on their colony size were inoculated into $4 \mathrm{ml}$ broth media and incubated at $37^{\circ} \mathrm{C}$ overnight. The nutrient or $\mathrm{BHI}$ broth was added to the overnight incubated bacterial suspension, and vortexed on a vortex mixer (Fisher Scientific. Ltd., England) for one minute to attained uniformly distribution. The vortexed bacterial suspension was adjusted to $0.5 \mathrm{McFarland}$ standard (Remel, Lenexa Kansas 66215 , USA) (equivalent to $1-2 \times 10^{8} \mathrm{CFU} / \mathrm{mL}$ ) through contrasting against white paper black line striped and was used for experiment within 15 minutes [26]. 
The $100 \mu \mathrm{l}$ of adjusted bacterial suspension was pipetted using a micropipette and applied on the surface of Mueller Hinton agar, and was swabbed at $60^{\circ}$ rotation to uniformly distribute bacteria throughout media surface using a cotton swab. The swabbed Mueller Hinton agar was allowed to stand for 15 minutes to provide time for the attachment of bacteria on the media. Then, the sterilized cork borer of $6 \mathrm{~mm}$ diameter was perforated with the swabbed media to create $6 \mathrm{~mm}$ diameter wells. At the time of punching media for different test bacteria, cork borer was sterilized by immersing in alcohol and burning with bunsen burner flames [27, 28]. The concentration of extracts for the experiment was determined based on a previous study on the plant [16]. The created wells were filled with $50 \mu \mathrm{l}$ extracts or fractions at a concentration of $400 \mathrm{mg} / \mathrm{ml}, 200 \mathrm{mg} / \mathrm{ml}$ and $100 \mathrm{mg} / \mathrm{ml}$, and negative control, but positive control disc (gentamicin) was placed on the media surface. After all wells on petri dishes were filled, and positive control was placed on petri dishes, then petri dishes were placed in the refrigerator at $4^{\circ} \mathrm{C}$ for $2 \mathrm{~h}$ to facilitate diffusion of extracts or fractions in the media. Subsequently, petri dishes were incubated at $37^{\circ} \mathrm{C}$ for $24 \mathrm{~h}$ in the incubator (BioTechnics India). The inhibition zone diameter after $24 \mathrm{~h}$ incubation was measured by a ruler in millimetre and recorded $[15,16,29]$. The experiment was done in triplicate.

\section{Antifungal activity}

The Candida albicans was cultured on sabouraud dextrose agar and incubated overnight. The overnight incubated yeast culture was inoculated into normal saline $(0.85 \%)$. The inoculated normal saline was vortexed and adjusted to $0.5 \mathrm{McF}$ arland standard (equivalent to $1-5 \times 10^{6} \mathrm{cells} / \mathrm{ml}$ ) by contrasting against white paper black line striped [30]. The $100 \mu \mathrm{l}$ adjusted Candida albicans suspension was pipetted using a micropipette and applied on the surface of sabouraud dextrose agar and swabbed at $60^{\circ}$ rotation to uniformly distribute yeast throughout media surface using a cotton swab. The swabbed sabouraud dextrose agar stands for 15 minutes to provide time for the attachment of yeast on the media. After that, the sterilized $6 \mathrm{~mm}$ diameter cork borer was perforated swabbed media to create a $6 \mathrm{~mm}$ diameter of wells [29]. The concentration of extracts for the experiment was determined based on a previous study on the plant [15]. The created wells were filled with the $50 \mu$ l extracts or fractions at concentration $400 \mathrm{mg} / \mathrm{ml}, 200 \mathrm{mg} / \mathrm{ml}$ and $100 \mathrm{mg} / \mathrm{ml}$, negative, and positive control. The inoculated petri dishes were placed in the refrigerator at $4^{\circ} \mathrm{C}$ for $2 \mathrm{~h}$ to facilitate diffusion of extracts or fractions in the media. Next to that, Petri dishes were incubated at $37^{\circ} \mathrm{C}$ for $24 \mathrm{~h}$ in the incubator. The inhibition zone diameter after $24 \mathrm{~h}$ incubation was measured by a ruler in millimetre and recorded $[15,16,29]$. The experiment was done in triplicate.

\section{Determination of minimum inhibitory concentration (MIC) for pathogenic bacteria}

The minimum inhibitory concentrations were determined using the broth microdilution technique for extracts or solvent fractions as their inhibition zones equal to or greater than $7 \mathrm{~mm}$ in agar well diffusion techniques [31]. The overnight cultured 3-5 distinct bacterial colonies were inoculated into $4 \mathrm{ml}$ Mueller Hinton broth and incubated at $37^{\circ} \mathrm{C}$ overnight. Overnight incubated bacterial suspension had been adjusted ( $0.5 \mathrm{McF}$ arland standard) was diluted at a ratio of 1:20 with Mueller Hinton broth $(0.5 \mathrm{ml}$ bacterial suspension was added to $9.5 \mathrm{ml}$ broth) and vortexed to have uniformly distributed bacterial suspension $\left(5 \times 10^{6} \mathrm{CFU} / \mathrm{ml}\right)$. The UV radiated sterile microtiter plate (Greiner Bio-One, Germany) wells were filled with $100 \mu$ l Mueller Hinton broth which commenced from well one to twelve. The serial double dilution technique was employed for extracts and fractions in broth filled wells. The serial double dilution was performed as $100 \mu$ l extracts or fractions were added to the first well and thoroughly mixed for five times by rinsing using micropipette and $100 \mu \mathrm{l}$ of the mixture was transferred to the second well using a new micropipette tip and thoroughly mixed as above. A $100 \mu$ of the second well mixture was pipetted using a new micropipette tip and transferred to third well then was thoroughly mixed. The process was continued until the tenth 
well and $100 \mu \mathrm{l}$ mixture of the tenth well was pipetted and discarded to have an equal volume of fluid in wells [26]. The twofold serially diluted concentrations of extract for the experiment were determined from a previous study on the plant. The serially diluted concentrations used in the experiment were $(200 \mathrm{mg} / \mathrm{ml}, 100 \mathrm{mg} / \mathrm{ml}, 50 \mathrm{mg} / \mathrm{ml}$, $25 \mathrm{mg} / \mathrm{ml}, 12.5 \mathrm{mg} / \mathrm{ml}, 6.25 \mathrm{mg} / \mathrm{ml}, 3.125 \mathrm{mg} / \mathrm{ml}, 1.5625 \mathrm{mg} / \mathrm{ml}, 0.78125 \mathrm{mg} / \mathrm{ml}$, and 0.3906mg/ml) [16]. The 100 $\mu \mathrm{l}$ broth filled eleventh and twentieth wells were used as growth and sterility control, respectively. The 10 $\mu$ diluted bacterial suspension ( $10 \%$ of $100 \mu$ l well volume) was pipetted to wells from eleventh to first wells to reduce contamination to sterility control and attained final concentration of $5 \times 10^{5} \mathrm{CFU} / \mathrm{ml}$ bacteria in each well, but $10 \mu \mathrm{l}$ broth was pipetted to twelfth well. Finally, microtiter plates were sealed using parafilm and incubated at $37^{\circ} \mathrm{C}$ for $24 \mathrm{~h}$ [26]. The incubated microtiter plate wells were filled with $0.01 \%$ resazurin sodium salt indicator from twelfth to first well and incubated for $2 \mathrm{~h}$ at $37^{\circ} \mathrm{C}$. The resazurin sodium salt reaction with actively growing microorganisms produces colour changes which are important to determine the MIC of extracts or fractions based on colour changes. The blue or purple colour appears if the growth of microorganisms is inhibited, while pink or colourless change is observed for those actively growing cells which reduced resazurin sodium salt to resorufin. Resazurin sodium salt solution was prepared by dissolving $0.01 \mathrm{gram}$ in $100 \mathrm{ml}$ sterile distilled water and filtered through $0.2 \mu$ pore size filter paper and stored in a dark container at $4^{\circ} \mathrm{C}$ refrigerator until use $[29,32]$. The experiment was performed in triplicate.

\section{Determination of minimum inhibitory concentration for pathogenic fungi}

Overnight cultured three colonies of yeast were inoculated into sabouraud dextrose broth and incubated at $37^{\circ} \mathrm{C}$ overnight. Overnight incubated yeast suspension had been adjusted ( $0.5 \mathrm{McFarland}$ standard) was diluted at a ratio of $1: 20$ with sabouraud dextrose broth $(0.5 \mathrm{ml}$ yeast suspension was added to $9.5 \mathrm{ml}$ broth) and vortexed to have uniformly distributed yeast suspension $\left(0.5-2.5 \times 10^{5} \mathrm{CFU} / \mathrm{ml}\right)$. The sterile microtiter plate wells were filled with $100 \mu \mathrm{l}$ sabouraud dextrose broth started from well one to twelve. The serial double dilution technique was employed for extracts and fractions in broth filled wells commenced from first to tenth wells. The serial double dilution was performed as $100 \mu$ l extracts or fractions were added to the first well and thoroughly mixed five times by rinsing using micropipette and $100 \mu \mathrm{l}$ of the mixture was transferred to the second well using a new micropipette tip and thoroughly mixed as above. A $100 \mu \mathrm{l}$ of the second well mixture was pipetted using a new micropipette tip and transferred to third well then was thoroughly mixed as above. The process was continued until the tenth well and $100 \mu \mathrm{l}$ mixture of the tenth well was pipetted and discarded to have an equal volume of fluid in wells [34]. The twofold serially diluted concentrations of extract for the experiment were determined from a previous study on the plant. The serial double dilution concentrations used in the experiment were $(200 \mathrm{mg} / \mathrm{ml}, 100 \mathrm{mg} / \mathrm{ml}, 50 \mathrm{mg} / \mathrm{ml}$, $25 \mathrm{mg} / \mathrm{ml}, 12.5 \mathrm{mg} / \mathrm{ml}, 6.25 \mathrm{mg} / \mathrm{ml}, 3.125 \mathrm{mg} / \mathrm{ml}, 1.5625 \mathrm{mg} / \mathrm{ml}, 0.78125 \mathrm{mg} / \mathrm{ml}$, and 0.3906mg/ml) [15]. The 100 $\mu \mathrm{l}$ broth filled eleventh and twentieth wells were used as growth and sterility control, respectively. The 10 $\mu$ l diluted yeast suspension ( $10 \%$ of $100 \mu$ l broth volume) was pipetted to wells from eleventh to first wells to reduce contamination on sterility control and attained final concentration of yeast suspension $\left(2.5 \times 10^{4} \mathrm{CFU} / \mathrm{ml}\right)$ in each well, but $10 \mu \mathrm{l}$ broth was pipetted to twelfth well. The filled microtiter plate wells were sealed by parafilm and incubated at $37^{\circ} \mathrm{C}$ for $24 \mathrm{~h}[26,34]$. The incubated microtiter plate wells were filled with $0.01 \%$ resazurin sodium salt indicator from twelfth to first well and incubated for $2 \mathrm{~h}$ at $37^{\circ} \mathrm{C}$. The MIC of extracts and fractions were determined as blue or purple resazurin colour changed to pink or colourless [29,32]. The experiment was done in triplicate.

\section{Determination of Minimum Bactericidal Concentration (MBC)}


The minimum bactericidal concentration was determined through sub-culturing of $10 \mu$ content of microtiter plate well which is greater or equal to the lowest minimum inhibitory concentration on the Mueller Hinton agar and incubated for $24 \mathrm{~h}$. After $24 \mathrm{~h}$ incubation, the petri dish was assessed for the presence of growth, and the minimum concentration of extracts or fractions with no visible growth was taken as minimum bactericidal concentration [33]. The experiment was done in triplicate.

\section{Determination of Minimum Fungicidal Concentration (MFC)}

The minimum fungicidal concentration was determined through sub-culturing of $10 \mu$ content of microtiter plate well which is greater or equal to the lowest minimum inhibitory concentration on the sabouraud dextrose agar and incubated for $24 \mathrm{~h}$. After $24 \mathrm{~h}$ incubation, the Petri dish was assessed for the presence of growth, and the minimum concentration of extracts or fractions with no visible growth was taken as minimum fungicidal concentration [33]. The experiment was done in triplicate.

\section{Data Analysis}

The data were entered into an excel spreadsheet for statistical analysis using Statistical Package for Social Science (SPSS) version 20. The descriptive statistics, one-way ANOVA, Tukey Post Hoc test, and linear regression $\mathrm{R}^{2}$ were utilized for statistical analysis and inference. The descriptive statistics were employed for calculation of group mean of inhibition zone diameter as Mean \pm SEM. The one-way ANOVA was performed to determine the significant difference among group means. One-way ANOVA was followed by Tukey Post Hoc test to determine where the significant difference occurred between groups. The linear regression $\mathrm{R}^{2}$ was calculated to determine the concentration dependence of crude extracts and solvent fractions on antimicrobial activities against test microorganisms. Statistically significant differences were declared at a p-value of less than 0.05 .

\section{Results}

\section{Antibacterial activity}

\section{Agar well diffusion assay}

The inhibition zone diameter was observed for crude extracts, solvent fractions, and positive control, but not for negative control. The highest inhibition zone diameter of crude methanol extract determined against gram-positive bacteria (17.33 $\mathrm{mm}$ against $S$. pyogenes) and gram-negative bacteria (14.67 mm against $P$. aeruginosa). However, the highest concentration of crude methanol extract against $K$. pneumoniae produced the lowest inhibition zone diameter of $12.67 \mathrm{~mm}$. The highest inhibition zone diameter of crude acetone extract observed against grampositive bacteria were $14.33 \mathrm{~mm}$ against $S$. pyogenes and gram-negative bacteria (13.33 $\mathrm{mm}$ against $E$. coli). Nevertheless, the highest concentration of crude acetone extract against $K$. pneumonia produced the lowest inhibition zone diameter of $11.67 \mathrm{~mm}$ (Table 1 and 2). The highest inhibition zone diameter of ethyl acetate fraction observed were against gram-positive (20.33 mm against $S$. aureus) and gram-negative bacteria (16.67 mm against $P$. aeruginosa). Whereas, $\mathrm{n}$-hexane fraction produced the lowest inhibition zone diameter and no antibacterial activity against $P$. aeruginosa. Additionally, ethyl acetate fraction produced the highest inhibition zone diameter than the crude extract of methanol, acetone, and other solvent fractions (Table 1, 2, 3, and 4). The highest inhibition zone diameter of ethyl acetate fraction observed against clinical isolate bacteria of gram-positive (17.67 $\mathrm{mm}$ against $S$. aureus) and gram-negative (14.67 $\mathrm{mm}$ against $E$. coli) (Table 5). 


\section{Agar well diffusion assay}

The inhibition zone diameter was observed for crude extracts, solvent fractions, and positive control, but not for negative control. The highest inhibition zone diameter of crude methanol extract determined against gram-positive bacteria (17.33 $\mathrm{mm}$ against $S$. pyogenes) and gram-negative bacteria (14.67 mm against $P$. aeruginosa). However, the highest concentration of crude methanol extract against $K$. pneumoniae produced the lowest inhibition zone diameter of $12.67 \mathrm{~mm}$. The highest inhibition zone diameter of crude acetone extract observed against grampositive bacteria were $14.33 \mathrm{~mm}$ against $S$. pyogenes and gram-negative bacteria (13.33 $\mathrm{mm}$ against $E$. coli). Nevertheless, the highest concentration of crude acetone extract against $K$. pneumonia produced the lowest inhibition zone diameter of $11.67 \mathrm{~mm}$ (Table 1 and 2). The highest inhibition zone diameter of ethyl acetate fraction observed were against gram-positive (20.33 mm against $S$. aureus) and gram-negative bacteria (16.67 mm against $P$. aeruginosa). Whereas, $\mathrm{n}$-hexane fraction produced the lowest inhibition zone diameter and no antibacterial activity against $P$. aeruginosa. Additionally, ethyl acetate fraction produced the highest inhibition zone diameter than the crude extract of methanol, acetone, and other solvent fractions (Table 1, 2, 3, and 4). The highest inhibition zone diameter of ethyl acetate fraction observed against clinical isolate bacteria of gram-positive (17.67 $\mathrm{mm}$ against $S$. aureus) and gram-negative (14.67 $\mathrm{mm}$ against $E$. coli) (Table 5).

Table 1: Mean inhibition zone diameter ( $\mathrm{mm}$ ) of Ricinus communis Linn leaf crude extracts against gram-positive bacteria.

\begin{tabular}{|c|c|c|c|c|c|c|c|}
\hline \multicolumn{2}{|c|}{ le extracts } & \multicolumn{2}{|l|}{ S. aureus } & \multicolumn{2}{|l|}{ S. agalactiae } & \multicolumn{2}{|l|}{ S. pyogenes } \\
\hline & & Mean \pm SEM & $\mathrm{R}^{2}$ & Mean \pm SEM & $\mathrm{R}^{2}$ & Mean \pm SEM & $\mathrm{R}^{2}$ \\
\hline \multirow[t]{3}{*}{ ranol } & $100 \mathrm{mg} / \mathrm{ml}$ & $10.67 \pm 0.333^{\mathrm{a} 3 \mathrm{c} 1 \mathrm{~d} 3}$ & \multirow{3}{*}{0.876} & $10.33 \pm 0.333^{\mathrm{a} 3 \mathrm{~d} 3}$ & \multirow{3}{*}{0.893} & $12.67 \pm 0.333^{\mathrm{a} 3 \mathrm{c} 2 \mathrm{~d} 3}$ & \multirow{3}{*}{0.831} \\
\hline & $200 \mathrm{mg} / \mathrm{ml}$ & $12.67 \pm 0.333^{a 3 b 1 d 1}$ & & $12.00 \pm 0.577^{\mathrm{a} 3 \mathrm{~d} 2}$ & & $15.67 \pm 0.333^{\mathrm{b} 2 \mathrm{~d} 1}$ & \\
\hline & $400 \mathrm{mg} / \mathrm{ml}$ & $15.00 \pm 0.577^{\mathrm{a} 3 \mathrm{~b} 3 \mathrm{c} 1}$ & & $14.67 \pm 0.333^{\mathrm{a} 1 \mathrm{~b} 3 \mathrm{c} 2}$ & & $17.33 \pm 0.333^{\mathrm{b} 3 \mathrm{c} 1}$ & \\
\hline rol & $10 \mu g$ & $20.67 \pm 0.333$ & & $16.67 \pm 0.333$ & & $16.67 \pm 0.333$ & \\
\hline \multirow{3}{*}{ one } & $100 \mathrm{mg} / \mathrm{ml}$ & $9.67 \pm 0.333^{\mathrm{a} 3 \mathrm{c} 1 \mathrm{~d} 3}$ & \multirow{3}{*}{0.916} & $9.67 \pm 0.333^{\mathrm{a} 3 \mathrm{c} 1 \mathrm{~d} 2}$ & \multirow{3}{*}{0.809} & $9.67 \pm 0.333^{\mathrm{a} 3 \mathrm{~b} 1 \mathrm{~d} 3}$ & \multirow{3}{*}{0.932} \\
\hline & $200 \mathrm{mg} / \mathrm{ml}$ & $11.33 \pm 0.333^{\mathrm{a} 3 \mathrm{~b} 1 \mathrm{~d} 2}$ & & $12.00 \pm 0.577^{\mathrm{a} 3 \mathrm{~b} 1}$ & & $11.67 \pm 0.333^{\mathrm{a} 3 \mathrm{~b} 1 \mathrm{~d} 2}$ & \\
\hline & $400 \mathrm{mg} / \mathrm{ml}$ & $13.67 \pm 0.333^{\mathrm{a} 3 \mathrm{~b} 3 \mathrm{c} 2}$ & & $13.67 \pm .333^{\mathrm{a} 2 \mathrm{~b} 2}$ & & $14.33 \pm 0.333^{\mathrm{a} 2 \mathrm{~b} 3 \mathrm{c} 2}$ & \\
\hline rol & $10 \mu g$ & $20.67 \pm 0.333$ & & $17.00 \pm 0.577$ & & $16.67 \pm .333$ & \\
\hline
\end{tabular}

Values expressed as Mean \pm SEM for $n=3$. The mean comparisons for different extracts and control

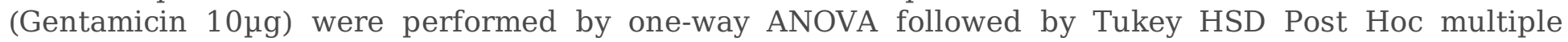

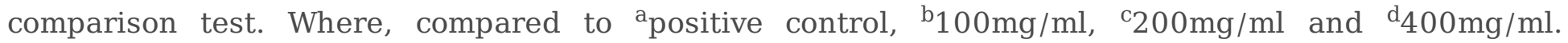
${ }^{1} \mathrm{P}<0.05,{ }^{2} \mathrm{P}<0.01,{ }^{3} \mathrm{P}<0.001$.

Table 2: Mean inhibition zone diameter $(\mathrm{mm})$ of Ricinus communis Linn leaf crude extracts against gram-negative bacteria. 


\begin{tabular}{|c|c|c|c|c|c|c|c|}
\hline \multicolumn{2}{|c|}{ e extract } & \multicolumn{2}{|l|}{ E. coli } & \multicolumn{2}{|l|}{$K$. pneumoniae } & \multicolumn{2}{|l|}{$P$. aeruginosa } \\
\hline & & Mean \pm SEM & $\mathrm{R}^{2}$ & Mean \pm SEM & $\mathrm{R}^{2}$ & Mean \pm SEM & $\mathrm{R}^{2}$ \\
\hline \multirow[t]{3}{*}{ lanol } & $100 \mathrm{mg} / \mathrm{ml}$ & $10.67 \pm 0.333^{\mathrm{a} 3 \mathrm{~d} 2}$ & \multirow{3}{*}{0.790} & $9.67 \pm 0.333^{\mathrm{d} 2}$ & \multirow{3}{*}{0.875} & $11.33 \pm 0.333^{\mathrm{a} 3 \mathrm{~d} 3}$ & \multirow{3}{*}{0.889} \\
\hline & $200 \mathrm{mg} / \mathrm{ml}$ & $12.00 \pm 0.577^{\mathrm{a} 3}$ & & $10.67 \pm 0.333^{\mathrm{d} 1}$ & & $12.67 \pm 0.333^{\mathrm{a} 3 \mathrm{~d} 1}$ & \\
\hline & $400 \mathrm{mg} / \mathrm{ml}$ & $13.67 \pm 0.333^{\mathrm{a} 3 \mathrm{~b} 2}$ & & $12.67 \pm .333^{\mathrm{a} 2 \mathrm{~b} 2 \mathrm{c} 1}$ & & $14.67 \pm 0.333^{\mathrm{a} 1 \mathrm{~b} 3 \mathrm{c} 1}$ & \\
\hline rol & $10 \mu g$ & $19.67 \pm 0.333$ & & $10.00 \pm 0.577$ & & $16.67 \pm 0.333$ & \\
\hline \multirow{3}{*}{ one } & $100 \mathrm{mg} / \mathrm{ml}$ & $9.67 \pm 0.333^{\mathrm{a} 3 \mathrm{c} 1 \mathrm{~d} 3}$ & \multirow{3}{*}{0.893} & $8.33 \pm 0.333^{\mathrm{c} 1 \mathrm{~d} 2}$ & \multirow{3}{*}{0.813} & $9.67 \pm 0.333^{a 3 d 2}$ & \multirow{3}{*}{0.843} \\
\hline & $200 \mathrm{mg} / \mathrm{ml}$ & $11.33 \pm 0.333^{\mathrm{a} 3 \mathrm{~b} 1 \mathrm{~d} 1}$ & & $10.33 \pm 0.333^{\mathrm{b} 1}$ & & $10.67 \pm 0.333^{\mathrm{a} 3 \mathrm{~d} 1}$ & \\
\hline & $400 \mathrm{mg} / \mathrm{ml}$ & $13.33 \pm 0.333^{a 3 b 3 c 1}$ & & $11.67 \pm 0.333^{\mathrm{b} 2}$ & & $12.33 \pm 0.333^{\mathrm{a} 3 \mathrm{~b} 2 \mathrm{c} 1}$ & \\
\hline$\overline{\mathrm{rol}}$ & $10 \mu g$ & $19.33 \pm 0.333$ & & $10.00 \pm 0.577$ & & $16.33 \pm 0.333$ & \\
\hline
\end{tabular}

Values expressed as Mean \pm SEM for $n=3$. The mean comparisons for different extracts and control

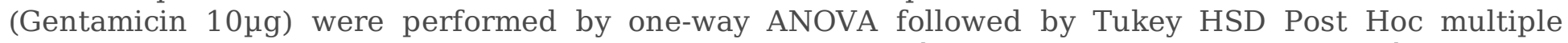

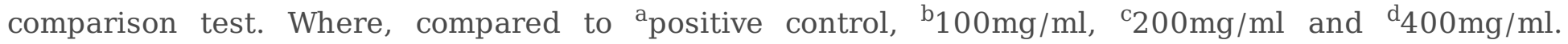
${ }^{1} \mathrm{P}<0.05,{ }^{2} \mathrm{P}<0.01,{ }^{3} \mathrm{P}<0.001$.

Table 3: Mean inhibition zone diameter $(\mathrm{mm})$ of Ricinus communis Linn leaf crude solvent fractions of methanol extract against gram-positive bacteria. 


\section{$\begin{array}{lll}\text { S. aureus S. agalactiae } & \text { S. pyogenes }\end{array}$}

\begin{tabular}{|c|c|c|c|c|c|c|c|}
\hline \multicolumn{2}{|c|}{ nt fractions } & Mean \pm SEM & $\mathrm{R}^{2}$ & Mean \pm SEM & $\mathrm{R}^{2}$ & Mean \pm SEM & $\mathrm{R}^{2}$ \\
\hline \multirow{3}{*}{ ane } & $100 \mathrm{mg} / \mathrm{ml}$ & $7.33 \pm 0.333^{\mathrm{a} 3 \mathrm{~d} 2}$ & \multirow{3}{*}{0.746} & $7.33 \pm 0.333^{\mathrm{a} 3 \mathrm{~d} 2}$ & \multirow{3}{*}{0.764} & $7.33 \pm 0.333^{\mathrm{a} 3 \mathrm{~d} 1}$ & \multirow{3}{*}{0.723} \\
\hline & $200 \mathrm{mg} / \mathrm{ml}$ & $8.67 \pm 0.333^{\mathrm{a} 3}$ & & $8.33 \pm 0.333^{\mathrm{a} 3}$ & & $8.33 \pm 0.333^{\mathrm{a} 3}$ & \\
\hline & $400 \mathrm{mg} / \mathrm{ml}$ & $9.67 \pm 0.333^{\mathrm{a} 3 \mathrm{~b} 2}$ & & $10.00 \pm 0.577^{\mathrm{a} 3 \mathrm{~b} 2}$ & & $9.33 \pm 0.333^{\mathrm{a} 3 \mathrm{~b} 1}$ & \\
\hline$\overline{\text { ol }}$ & $10 \mu g$ & $20.33 \pm 0.333$ & & $17.33 \pm 0.333$ & & $16.67 \pm 0.333$ & \\
\hline \multirow{3}{*}{ oform } & $100 \mathrm{mg} / \mathrm{ml}$ & $7.33 \pm 0.333^{\mathrm{a} 3 \mathrm{c} 1 \mathrm{~d} 2}$ & \multirow{3}{*}{0.750} & $7.67 \pm 0.333^{\mathrm{a} 3 \mathrm{c} 1 \mathrm{~d} 2}$ & \multirow{3}{*}{0.754} & $7.33 \pm 0.333^{\mathrm{a} 3 \mathrm{c} 2 \mathrm{~d} 3}$ & \multirow{3}{*}{0.750} \\
\hline & $200 \mathrm{mg} / \mathrm{ml}$ & $9.67 \pm 0.333^{\mathrm{a} 3 \mathrm{~b} 1}$ & & $9.67 \pm 0.333^{\mathrm{a} 3 \mathrm{~b} 1}$ & & $9.67 \pm 0.333^{\mathrm{a} 3 \mathrm{~b} 2}$ & \\
\hline & $400 \mathrm{mg} / \mathrm{ml}$ & $10.67 \pm 0.333^{\mathrm{a} 3 \mathrm{~b} 2}$ & & $10.67 \pm 0.333^{\mathrm{a} 3 \mathrm{~b} 2}$ & & $10.67 \pm 0.333^{\mathrm{a} 3 \mathrm{~b} 3}$ & \\
\hline$\overline{\text { ol }}$ & $10 \mu \mathrm{g}$ & $21.00 \pm 0.577$ & & $17.00 \pm 0.577$ & & $17.33 \pm 0.333$ & \\
\hline \multirow{3}{*}{ te } & $100 \mathrm{mg} / \mathrm{ml}$ & $15.33 \pm 0.333^{\mathrm{a} 3 \mathrm{c} 2 \mathrm{~d} 3}$ & \multirow{3}{*}{0.928} & $12.67 \pm 0.333^{\mathrm{a} 3 \mathrm{c} 1 \mathrm{~d} 3}$ & \multirow{3}{*}{0.898} & $13.33 \pm 0.333^{\mathrm{a} 2 \mathrm{c} 2 \mathrm{~d} 3}$ & \multirow{3}{*}{0.864} \\
\hline & $200 \mathrm{mg} / \mathrm{ml}$ & $17.67 \pm 0.333^{\mathrm{a} 2 \mathrm{~b} 2 \mathrm{~d} 2}$ & & $15.00 \pm 0.577^{\mathrm{a} 1 \mathrm{~b} 1 \mathrm{~d} 2}$ & & $16.33 \pm 0.333^{\mathrm{b} 3 \mathrm{c} 1}$ & \\
\hline & $400 \mathrm{mg} / \mathrm{ml}$ & $20.33 \pm 0.333^{\mathrm{b} 3 \mathrm{c} 2}$ & & $17.67 \pm 0.333^{\mathrm{b} 3 \mathrm{c} 2}$ & & $18.33 \pm 0.333^{\mathrm{b} 3 \mathrm{c} 1}$ & \\
\hline ol & $10 \mu \mathrm{g}$ & $20.67 \pm 0.333$ & & $17.33 \pm 0.333$ & & $17.00 \pm 0.577$ & \\
\hline \multirow[t]{3}{*}{ Jus } & $100 \mathrm{mg} / \mathrm{ml}$ & $12.67 \pm 0.333^{\mathrm{a} 3 \mathrm{~d} 2}$ & \multirow{3}{*}{0.893} & $10.67 \pm 0.333^{\mathrm{a} 3 \mathrm{c} 1 \mathrm{~d} 3}$ & \multirow{3}{*}{0.893} & $13.67 \pm 0.333^{\mathrm{a} 3 \mathrm{c} 1 \mathrm{~d} 3}$ & \multirow{3}{*}{0.916} \\
\hline & $200 \mathrm{mg} / \mathrm{ml}$ & $14.33 \pm 0.333^{\mathrm{a} 3 \mathrm{~d} 1}$ & & $12.33 \pm 0.333^{\mathrm{a} 3 \mathrm{~b} 1 \mathrm{~d} 1}$ & & $15.33 \pm 0.333^{\mathrm{a} 1 \mathrm{~b} 1 \mathrm{~d} 1}$ & \\
\hline & $400 \mathrm{mg} / \mathrm{ml}$ & $16.33 \pm 0.333^{\mathrm{a} 2 \mathrm{~b} 2 \mathrm{~d} 1}$ & & $14.33 \pm 0.333^{\mathrm{a} 2 \mathrm{~b} 3 \mathrm{c} 1}$ & & $17.33 \pm 0.333^{\mathrm{b} 3 \mathrm{c} 1}$ & \\
\hline ol & $10 \mu g$ & $20.67 \pm 0.667$ & & $17.33 \pm 0.333$ & & $17.33 \pm 0.333$ & \\
\hline
\end{tabular}

Values expressed as Mean $\pm \mathrm{SEM}$ for $\mathrm{n}=3$. The mean comparisons for different crude methanol extract's

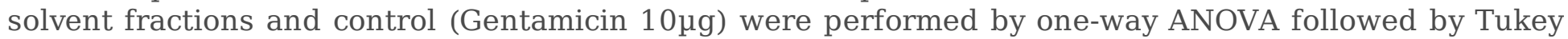
HSD Post Hoc multiple comparison test. Where, compared to apositive control, b $100 \mathrm{mg} / \mathrm{ml}$, ${ }^{\mathrm{c}} 200 \mathrm{mg} / \mathrm{ml}$, and ${ }^{\mathrm{d}} 400 \mathrm{mg} / \mathrm{ml} .{ }^{1} \mathrm{P}<0.05,{ }^{2} \mathrm{P}<0.01,{ }^{3} \mathrm{P}<0.001$.

Table 4: Mean inhibition zone diameter $(\mathrm{mm})$ of Ricinus communis Linn leaf crude solvent fractions of methanol extract against gram-negative bacteria. 

E. coli
K. pneumoniae
P. aeruginosa

эnt fractions

\begin{tabular}{lllll}
\hline Mean \pm SEM & $R^{2}$ & Mean \pm SEM & $R^{2}$ & Mean \pm SEM
\end{tabular}

\begin{tabular}{|c|c|c|c|c|c|c|c|}
\hline \multirow{3}{*}{ xane } & $100 \mathrm{mg} / \mathrm{ml}$ & $7.33 \pm 0.333^{\mathrm{a} 3 \mathrm{~d} 2}$ & \multirow{3}{*}{0.764} & $7.33 \pm 0.333^{\mathrm{a} 2 \mathrm{~d} 2}$ & \multirow{3}{*}{0.795} & -- & \\
\hline & $200 \mathrm{mg} / \mathrm{ml}$ & $8.33 \pm 0.333^{\mathrm{a} 3}$ & & $8.33 \pm 0.333$ & & -- & \\
\hline & $400 \mathrm{mg} / \mathrm{ml}$ & $10.00 \pm 0.577^{\mathrm{a} 3 \mathrm{~b} 2}$ & & $9.67 \pm 0.333^{b 2}$ & & -- & \\
\hline rol & $10 \mu g$ & $19.67 \pm 0.333$ & & $9.67 \pm 0.333$ & & $17.33 \pm 0.333$ & \\
\hline \multirow{3}{*}{ roform } & $100 \mathrm{mg} / \mathrm{ml}$ & $7.67 \pm 0.333^{\mathrm{a} 3 \mathrm{c} 1 \mathrm{~d} 2}$ & \multirow{3}{*}{0.816} & $8.67 \pm 0.333^{d 2}$ & \multirow{3}{*}{0.875} & $8.67 \pm 0.333^{\mathrm{a} 3 \mathrm{~d} 2}$ & \multirow{3}{*}{0.875} \\
\hline & $200 \mathrm{mg} / \mathrm{ml}$ & $9.33 \pm 0.333^{\mathrm{a} 3 \mathrm{~b} 1}$ & & $9.67 \pm 0.333^{\mathrm{d} 1}$ & & $9.67 \pm 0.333^{\mathrm{a} 3 \mathrm{~d} 1}$ & \\
\hline & $400 \mathrm{mg} / \mathrm{ml}$ & $10.67 \pm 0.333^{\mathrm{a} 3 \mathrm{~b} 2}$ & & $11.67 \pm 0.333^{\mathrm{b} 2 \mathrm{c} 1}$ & & $11.67 \pm 0.333^{a 3 b 2 c 1}$ & \\
\hline rol & $10 \mu \mathrm{g}$ & $19.33 \pm 0.333$ & & $10.00 \pm 0.577$ & & $17.33 \pm 0.333$ & \\
\hline \multirow{3}{*}{$\begin{array}{l}1 \\
\text { ate }\end{array}$} & $100 \mathrm{mg} / \mathrm{ml}$ & $10.67 \pm 0.333^{a 3 c 1 d 3}$ & \multirow{3}{*}{0.898} & $10.67 \pm 0.333^{\mathrm{c} 1 \mathrm{~d} 3}$ & \multirow{3}{*}{0.945} & $10.67 \pm 0.333^{\mathrm{a} 3 \mathrm{c} 2 \mathrm{~d} 3}$ & \multirow{3}{*}{0.949} \\
\hline & $200 \mathrm{mg} / \mathrm{ml}$ & $13.00 \pm 0.577^{\mathrm{a} 3 \mathrm{~b} 1 \mathrm{~d} 2}$ & & $12.67 \pm 0.333^{\mathrm{a} 2 \mathrm{~b} 1 \mathrm{~d} 2}$ & & $13.33 \pm 0.333^{\mathrm{a} 2 \mathrm{~b} 2 \mathrm{~d} 2}$ & \\
\hline & $400 \mathrm{mg} / \mathrm{ml}$ & $15.67 \pm 0.333^{a 2 b 3 c 2}$ & & $15.67 \pm 0.333^{a 3 b 3 d} 2$ & & $16.67 \pm 0.333^{\mathrm{b} 3 \mathrm{c} 2}$ & \\
\hline rol & $10 \mu \mathrm{g}$ & $19.67 \pm 0.333$ & & $9.67 \pm 0.333$ & & $17.00 \pm 0.577$ & \\
\hline \multirow[t]{3}{*}{ 3ous } & $100 \mathrm{mg} / \mathrm{ml}$ & $10.33 \pm 0.333^{\mathrm{a} 3 \mathrm{~d} 2}$ & \multirow{3}{*}{0.764} & $10.33 \pm 0.333^{\mathrm{d} 2}$ & \multirow{3}{*}{0.795} & $10.67 \pm 0.333^{\mathrm{a} 3 \mathrm{~d} 2}$ & \multirow{3}{*}{0.843} \\
\hline & $200 \mathrm{mg} / \mathrm{ml}$ & $11.33 \pm 0.333^{\mathrm{a} 3}$ & & $11.33 \pm 0.333^{\mathrm{a} 1}$ & & $11.67 \pm 0.333^{\mathrm{a} 3}$ & \\
\hline & $400 \mathrm{mg} / \mathrm{ml}$ & $13.00 \pm 0.577^{\mathrm{a} 3 \mathrm{~b} 2}$ & & $12.67 \pm 0.333^{\mathrm{a} 2 \mathrm{~b} 2}$ & & $13.33 \pm 0.333^{\mathrm{a} 2 \mathrm{~b} 2}$ & \\
\hline rol & $10 \mu g$ & $19.67 \pm 0.333$ & & $9.67 \pm 0.333$ & & $17.00 \pm 0.577$ & \\
\hline
\end{tabular}

Values expressed as Mean \pm SEM for $n=3$. The mean comparisons for different crude methanol extract's solvent fractions and control (Gentamicin 10 $\mathrm{g}$ ) were performed by one-way ANOVA followed by Tukey HSD Post Hoc multiple comparison test. Where, compared to apositive control, ${ }^{b} 100 \mathrm{mg} / \mathrm{ml},{ }^{\mathrm{c}} 200 \mathrm{mg} / \mathrm{ml}$ and ${ }^{\mathrm{d}} 400 \mathrm{mg} / \mathrm{ml} .{ }^{1} \mathrm{P}<0.05,{ }^{2} \mathrm{P}<0.01,{ }^{3} \mathrm{P}<0.001$. No activity $=--$

Table-5: Mean inhibition zone diameter ( $\mathrm{mm}$ ) of Ricinus communis Linn leaf crude extracts and solvent fractions of methanol extract against clinical isolate bacteria. 


\begin{tabular}{|c|c|c|c|c|c|}
\hline \multirow{2}{*}{\multicolumn{2}{|c|}{$\begin{array}{l}\text { Crude extracts and } \\
\text { Solvent fractions }\end{array}$}} & \multicolumn{2}{|c|}{ Clinical $E$. coli isolate } & \multicolumn{2}{|c|}{ Clinical $S$. aureus isolate } \\
\hline & & Mean \pm SEM & $\mathrm{R}^{2}$ & Mean \pm SEM & $\mathrm{R}^{2}$ \\
\hline \multirow[t]{3}{*}{ Methanol } & $100 \mathrm{mg} / \mathrm{ml}$ & $7.67 \pm 0.333^{\mathrm{a} 3 \mathrm{~d} 2}$ & \multirow{3}{*}{0.875} & $9.33 \pm 0.333^{\mathrm{a} 3 \mathrm{~d} 2}$ & \multirow{3}{*}{0.735} \\
\hline & $200 \mathrm{mg} / \mathrm{ml}$ & $8.67 \pm 0.333^{\mathrm{a} 3 \mathrm{~d} 1}$ & & $10.67 \pm 0.333^{\mathrm{a} 3}$ & \\
\hline & $400 \mathrm{mg} / \mathrm{ml}$ & $10.67 \pm 0.333^{\mathrm{a} 3 \mathrm{~b} 2 \mathrm{c} 1}$ & & $12.00 \pm 0.577^{\mathrm{a} 3 \mathrm{~b} 2}$ & \\
\hline Control & $10 \mu g$ & $19.67 \pm 0.333$ & & $20.33 \pm 0.333$ & \\
\hline \multirow[t]{3}{*}{ Acetone } & $100 \mathrm{mg} / \mathrm{ml}$ & $7.67 \pm 0.333^{\mathrm{a} 3 \mathrm{~d} 2}$ & \multirow{3}{*}{0.875} & $7.33 \pm 0.333^{\mathrm{a} 3 \mathrm{~d} 2}$ & \multirow{3}{*}{0.860} \\
\hline & $200 \mathrm{mg} / \mathrm{ml}$ & $8.67 \pm 0.333^{\mathrm{a} 3 \mathrm{~d} 1}$ & & $8.67 \pm 0.333^{\mathrm{a} 3 \mathrm{~d} 1}$ & \\
\hline & $400 \mathrm{mg} / \mathrm{ml}$ & $10.67 \pm 0.333^{\mathrm{a} 3 \mathrm{~b} 2 \mathrm{c} 1}$ & & $11.00 \pm 0.577^{\mathrm{a} 3 \mathrm{~b} 2 \mathrm{c} 1}$ & \\
\hline Control & $10 \mu g$ & $19.33 \pm 0.333$ & & $20.33 \pm 0.333$ & \\
\hline \multirow{3}{*}{ n-hexane } & $100 \mathrm{mg} / \mathrm{ml}$ & $7.33 \pm 0.333^{\mathrm{a} 3 \mathrm{~d} 1}$ & \multirow{3}{*}{0.723} & $7.33 \pm 0.333^{\mathrm{a} 3 \mathrm{~d} 2}$ & \multirow{3}{*}{0.795} \\
\hline & $200 \mathrm{mg} / \mathrm{ml}$ & $8.33 \pm 0.333^{\mathrm{a} 3}$ & & $8.33 \pm 0.333^{a 3}$ & \\
\hline & $400 \mathrm{mg} / \mathrm{ml}$ & $9.33 \pm 0.333^{\mathrm{a} 3 \mathrm{~b} 1}$ & & $9.67 \pm 0.333^{\mathrm{a} 3 \mathrm{~b} 2}$ & \\
\hline Control & $10 \mu g$ & $19.33 \pm 0.333$ & & $19.67 \pm 0.333$ & \\
\hline \multirow{3}{*}{ Chloroform } & $100 \mathrm{mg} / \mathrm{ml}$ & $7.33 \pm 0.333^{\mathrm{a} 3 \mathrm{~d} 1}$ & \multirow{3}{*}{0.723} & $8.33 \pm 0.333^{\mathrm{a} 3 \mathrm{~d} 2}$ & \\
\hline & $200 \mathrm{mg} / \mathrm{ml}$ & $8.33 \pm 0.333^{\mathrm{a} 3}$ & & $9.33 \pm 0.333^{\mathrm{a} 3}$ & \\
\hline & $400 \mathrm{mg} / \mathrm{ml}$ & $9.33 \pm 0.333^{\mathrm{a} 3 \mathrm{~b} 1}$ & & $10.67 \pm 0.333^{\mathrm{a} 3 \mathrm{~b} 2}$ & \\
\hline Control & $10 \mu g$ & $19.33 \pm 0.333$ & & $19.67 \pm 0.333$ & \\
\hline \multirow{3}{*}{ Ethyl acetate } & $100 \mathrm{mg} / \mathrm{ml}$ & $11.33 \pm 0.333^{\mathrm{a} 3 \mathrm{~d} 2}$ & \multirow{3}{*}{0.804} & $13.00 \pm 0.577^{\mathrm{a} 3 \mathrm{c} 1 \mathrm{~d} 3}$ & \multirow{3}{*}{0.842} \\
\hline & $200 \mathrm{mg} / \mathrm{ml}$ & $13.00 \pm 0.577^{\mathrm{a} 3}$ & & $15.67 \pm 0.333^{\mathrm{a} 2 \mathrm{~b} 2 \mathrm{~d} 1}$ & \\
\hline & $400 \mathrm{mg} / \mathrm{ml}$ & $14.67 \pm 0.333^{\mathrm{a} 2 \mathrm{~b} 2}$ & & $17.67 \pm 0.333^{\mathrm{b} 3 \mathrm{c} 2}$ & \\
\hline Control & $10 \mu g$ & $19.00 \pm 0.577$ & & $19.33 \pm 0.333$ & \\
\hline \multirow[t]{3}{*}{ Aqueous } & $100 \mathrm{mg} / \mathrm{ml}$ & $7.67 \pm 0.333^{\mathrm{a} 3 \mathrm{~d} 2}$ & \multirow{3}{*}{0.843} & $12.00 \pm 0.577^{\mathrm{a} 3 \mathrm{~d} 2}$ & \multirow{3}{*}{0.766} \\
\hline & $200 \mathrm{mg} / \mathrm{ml}$ & $8.67 \pm 0.333^{\mathrm{a} 3 \mathrm{~d} 1}$ & & $14.00 \pm 0.577^{\mathrm{a} 3}$ & \\
\hline & $400 \mathrm{mg} / \mathrm{ml}$ & $10.33 \pm 0.333^{\mathrm{a} 3 \mathrm{~b} 2 \mathrm{~d} 1}$ & & $15.67 \pm 0.333^{\mathrm{a} 2 \mathrm{~b} 2}$ & \\
\hline Control & $10 \mu g$ & $19.67 \pm 0.333$ & & $19.67 \pm 0.333$ & \\
\hline
\end{tabular}

Values expressed as Mean \pm SEM for $n=3$. The mean comparisons for different extracts, crude methanol

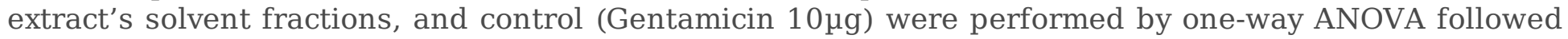
by Tukey HSD Post Hoc multiple comparison test. Where, compared to ${ }^{a}$ positive control, ${ }^{b} 100 \mathrm{mg} / \mathrm{ml}$, ${ }^{\mathrm{c}} 200 \mathrm{mg} / \mathrm{ml}$, and ${ }^{\mathrm{d}} 400 \mathrm{mg} / \mathrm{ml} .{ }^{1} \mathrm{P}<0.05,{ }^{2} \mathrm{P}<0.01,{ }^{3} \mathrm{P}<0.001$. 


\section{Antifungal activity}

\section{Agar well diffusion assay}

The assay determined inhibition zone diameter for crude extracts, solvent fractions, and positive control, but not for negative control. The aqueous fraction exhibited the highest inhibition zone diameter of $21 \mathrm{~mm}$, but no inhibition zone diameter observed for n-hexane and chloroform fractions against $C$. albicans (Table 6).

Table 6: Mean inhibition zone diameter (mm) of Ricinus communis Linn leaf crude extracts and solvent fractions of methanol extract against fungi. 


\section{fraction}

Mean $\pm \mathrm{SEM} \quad \mathrm{R}^{2}$

\begin{tabular}{|c|c|c|c|}
\hline \multirow[t]{3}{*}{ Methanol extract } & $100 \mathrm{mg} / \mathrm{ml}$ & $7.33 \pm 0.333^{\mathrm{a} 3 \mathrm{~d} 2}$ & \multirow{3}{*}{0.735} \\
\hline & $200 \mathrm{mg} / \mathrm{ml}$ & $8.67 \pm 0.333^{\mathrm{a} 3}$ & \\
\hline & $400 \mathrm{mg} / \mathrm{ml}$ & $10.00 \pm 0.577^{\mathrm{a} 3 \mathrm{~b} 2}$ & \\
\hline Control & $20 \mu \mathrm{g} / \mathrm{ml}$ & $23.33 \pm 0.333$ & \\
\hline \multirow[t]{3}{*}{ Acetone extract } & $100 \mathrm{mg} / \mathrm{ml}$ & $7.33 \pm 0.333^{\mathrm{a} 3 \mathrm{~d} 2}$ & \multirow{3}{*}{0.746} \\
\hline & $200 \mathrm{mg} / \mathrm{ml}$ & $8.67 \pm 0.333^{\mathrm{a} 3}$ & \\
\hline & $400 \mathrm{mg} / \mathrm{ml}$ & $9.67 \pm 0.333^{\mathrm{a} 3 \mathrm{~b} 2}$ & \\
\hline Control & $20 \mu \mathrm{g} / \mathrm{ml}$ & $22.67 \pm 0.333$ & \\
\hline \multirow[t]{3}{*}{ n-hexane fraction } & $100 \mathrm{mg} / \mathrm{ml}$ & -- & \\
\hline & $200 \mathrm{mg} / \mathrm{ml}$ & -- & \\
\hline & $400 \mathrm{mg} / \mathrm{ml}$ & -- & \\
\hline Control & $20 \mu \mathrm{g} / \mathrm{ml}$ & $23.33 \pm 0.333$ & \\
\hline \multirow[t]{3}{*}{ Chloroform fraction } & $100 \mathrm{mg} / \mathrm{ml}$ & -- & \\
\hline & $200 \mathrm{mg} / \mathrm{ml}$ & -- & \\
\hline & $400 \mathrm{mg} / \mathrm{ml}$ & -- & \\
\hline Control & $20 \mu \mathrm{g} / \mathrm{ml}$ & $23.33 \pm 0.333$ & \\
\hline \multirow{3}{*}{ Ethyl acetate fraction } & $100 \mathrm{mg} / \mathrm{ml}$ & $11.33 \pm 0.333^{a 3 b 1 d}$ & \multirow{3}{*}{0.890} \\
\hline & $200 \mathrm{mg} / \mathrm{ml}$ & $13.33 \pm 0.333^{a 3 b 1 d 1}$ & \\
\hline & $400 \mathrm{mg} / \mathrm{ml}$ & $15.33 \pm 0.333^{\mathrm{a} 3 \mathrm{~b} 3 \mathrm{c} 1}$ & \\
\hline Control & $20 \mu \mathrm{g} / \mathrm{ml}$ & $22.67 \pm 0.333$ & \\
\hline \multirow[t]{3}{*}{ Aqueous fraction } & $100 \mathrm{mg} / \mathrm{ml}$ & $14.67 \pm 0.333^{a 3 c 1 d} 3$ & \multirow{3}{*}{0.928} \\
\hline & $200 \mathrm{mg} / \mathrm{ml}$ & $17.00 \pm 0.577^{a 3 b 1 d 2}$ & \\
\hline & $400 \mathrm{mg} / \mathrm{ml}$ & $21.00 \pm 0.577^{\mathrm{a} 1 \mathrm{~b} 3 \mathrm{c} 2}$ & \\
\hline Control & $20 \mu \mathrm{g} / \mathrm{ml}$ & $23.33 \pm 0.333$ & \\
\hline
\end{tabular}

Values expressed as Mean \pm SEM for $n=3$. The mean comparisons for different extracts, crude methanol

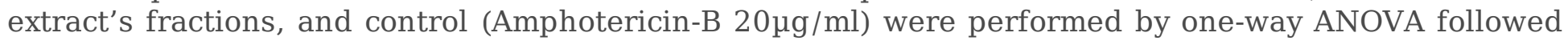
by Tukey HSD Post Hoc multiple comparison test. Where, compared to apositive control, b $100 \mathrm{mg} / \mathrm{ml}$, ${ }^{\mathrm{c}} 200 \mathrm{mg} / \mathrm{ml}$, and ${ }^{\mathrm{d}} 400 \mathrm{mg} / \mathrm{ml} .{ }^{1} \mathrm{P}<0.05,{ }^{2} \mathrm{P}<0.01,{ }^{3} \mathrm{P}<0.001$. No activity = -against pathogenic bacteria. 
The minimum inhibitory concentration of methanol crude extract ranging from $6.25 \mathrm{mg} / \mathrm{ml}(S$. aureus) to $25 \mathrm{mg} / \mathrm{ml}$ (E. coli, K. pneumoniae, P. aeruginosa) and acetone crude extract ranging from $8.33 \mathrm{mg} / \mathrm{ml}$ (S. pyogenes) to $100 \mathrm{mg} / \mathrm{ml}$ (K. pneumoniae). Also, minimum inhibitory concentration ethyl acetate fraction ranging from $1.5625 \mathrm{mg} / \mathrm{ml}$ (S. aureus) to $12.5 \mathrm{mg} / \mathrm{ml}$ (P. aeruginosa) and for aqueous fraction ranging from $6.25 \mathrm{mg} / \mathrm{ml}(S$. aureus and S. pyogenes) to $66.67 \mathrm{mg} / \mathrm{ml}$ (K. pneumoniae) (Table 7 and 8 ). The minimum inhibitory concentration for clinical isolate bacteria ranging from $3.125 \mathrm{mg} / \mathrm{ml}$ of ethyl acetate fraction (S. aureus) to $100 \mathrm{mg} / \mathrm{ml}$ of $\mathrm{n}$-hexane and chloroform fractions (S. aureus and E. coli) (Table 9).

\section{Determination of minimum bactericidal concentration of crude extracts and solvent fractions of methanol extract.}

The MBC of methanol extract ranging from $100 \mathrm{mg} / \mathrm{ml}$ (gram-positive bacteria) to $200 \mathrm{mg} / \mathrm{ml}$ ( $P$. aeruginosa) and was not detected in E. coli and K. pneumoniae. The minimum bactericidal concentration of acetone extract was $200 \mathrm{mg} / \mathrm{ml}$ in gram-positive bacteria, but not detected in gram-negative bacteria. The minimum bactericidal concentration of $\mathrm{n}$-hexane and chloroform fractions were not detected. However, minimum bactericidal concentration ethyl acetate fraction ranging from $25 \mathrm{mg} / \mathrm{ml}$ (S. aureus and S. agalactiae) to $200 \mathrm{mg} / \mathrm{ml}$ (E. coli and K. pneumoniae), and in clinical isolate bacteria ranging from $88.33 \mathrm{mg} / \mathrm{ml}$ (S. aureus) to $200 \mathrm{mg} / \mathrm{ml}$ (E. coli) (Table $7,8,9)$.

Table7: MIC and MBC of crude extracts and solvent fractions against gram-positive bacteria.

\begin{tabular}{|c|c|c|c|c|}
\hline \multirow{2}{*}{$\begin{array}{l}\text { Test extract } \\
\text { fraction }\end{array}$} & \multirow[t]{2}{*}{ Activities } & S. aureus & S. agalactiae & S. pyogenes \\
\hline & & $\begin{array}{l}\text { MeantSEM } \\
(\mathrm{mg} / \mathrm{ml})\end{array}$ & $\begin{array}{l}\text { MeantSEM } \\
(\mathrm{mg} / \mathrm{ml})\end{array}$ & $\begin{array}{l}\text { MeantSEM } \\
(\mathrm{mg} / \mathrm{ml})\end{array}$ \\
\hline \multirow[t]{2}{*}{ Methanol extract } & MIC & $6.25 \pm 0.000$ & $12.500 \pm 0.000$ & $6.25 \pm 3.1250$ \\
\hline & $\mathrm{MBC}$ & $100.00 \pm 0.000$ & $100.00 \pm 0.000$ & $100.00 \pm 0.000$ \\
\hline \multirow[t]{2}{*}{ Acetone extract } & MIC & $18.75 \pm 6.25$ & $16.67 \pm 4.167$ & $8.33 \pm 2.083$ \\
\hline & MBC & $200.00 \pm 0.000$ & $200.00 \pm 0.000$ & $200.00 \pm 0.000$ \\
\hline \multirow[t]{2}{*}{ n-hexane fraction } & MIC & $100.00 \pm 0.00$ & $100.00 \pm 0.00$ & $100.00 \pm 0.00$ \\
\hline & MBC & $\mathrm{ND}$ & $\mathrm{ND}$ & $\mathrm{ND}$ \\
\hline \multirow[t]{2}{*}{ Chloroform fraction } & MIC & $83.33 \pm 16.667$ & $16.67 \pm 4.167$ & $16.67 \pm 4.167$ \\
\hline & MBC & ND & ND & $\mathrm{ND}$ \\
\hline \multirow[t]{2}{*}{ Ethyl acetate fraction } & MIC & $1.5625 \pm 0.00$ & $4.17 \pm 1.0417$ & $3.125 \pm 0.000$ \\
\hline & MBC & $25.00 \pm 0.000$ & $25.00 \pm 0.000$ & $50.00 \pm 0.000$ \\
\hline \multirow[t]{2}{*}{ Aqueous fraction } & $\mathrm{MIC}$ & $6.25 \pm 0.00$ & $12.50 \pm 0.000$ & $6.250 \pm 0.000$ \\
\hline & $\mathrm{MBC}$ & $200.00 \pm 0.000$ & $200.00 \pm .000$ & $200.00 \pm .000$ \\
\hline
\end{tabular}

Mean value expressed as Mean \pm SEM $(n=3), N D=$ not detected

Table 8: MIC and MBC of crude extracts and solvent fractions against gram-negative bacteria. 


\begin{tabular}{|c|c|c|c|c|}
\hline \multirow{2}{*}{$\begin{array}{l}\text { Test extract } \\
\text { fraction }\end{array}$} & \multirow{2}{*}{ Activities } & E. coli & $K$. pneumoniae & $P$. aeruginosa \\
\hline & & $\begin{array}{l}\text { Mean } \pm \text { SEM } \\
(\mathrm{mg} / \mathrm{ml})\end{array}$ & $\begin{array}{l}\text { Mean } \pm \text { SEM } \\
(\mathrm{mg} / \mathrm{ml})\end{array}$ & $\begin{array}{l}\text { Mean } \pm \text { SEM } \\
(\mathrm{mg} / \mathrm{ml})\end{array}$ \\
\hline \multirow[t]{2}{*}{ Methanol extract } & MIC & $25.00 \pm 0.000$ & $25.00 \pm 0.000$ & $25.00 \pm 0.000$ \\
\hline & MBC & ND & ND & $200.00 \pm 0.000$ \\
\hline \multirow[t]{2}{*}{ Acetone extract } & MIC & $66.67 \pm 16.667$ & $100.00 \pm 0.000$ & $66.67 \pm 16.667$ \\
\hline & MBC & ND & ND & ND \\
\hline \multirow[t]{2}{*}{ n-hexane fraction } & MIC & $100.00 \pm 0.000$ & $100.00 \pm 0.000$ & NT \\
\hline & MBC & ND & ND & NT \\
\hline \multirow[t]{2}{*}{ Chloroform fraction } & MIC & $83.33 \pm 16.667$ & $83.33 \pm 16.667$ & $50.00 \pm 0.000$ \\
\hline & MBC & ND & ND & ND \\
\hline \multirow[t]{2}{*}{ Ethyl acetate fraction } & MIC & $4.17 \pm 1.0417$ & $6.250 \pm 0.000$ & $12.50 \pm 0.000$ \\
\hline & MBC & $200.00 \pm 0.000$ & $200.00 \pm 0.000$ & $50.00 \pm 0.000$ \\
\hline \multirow[t]{2}{*}{ Aqueous fraction } & MIC & $50.00 \pm 0.000$ & $66.67 \pm 16.667$ & $25.00 \pm 0.000$ \\
\hline & MBC & ND & ND & $200.00 \pm 0.000$ \\
\hline
\end{tabular}

Mean value expressed as Mean \pm SEM $(n=3) \mathrm{ND}=$ not detected, $\mathrm{NT}=$ not tested

Table 9: MIC and MBC of crude extracts and solvent fractions against clinical isolate bacteria.

\begin{tabular}{llll}
\hline Test extract and fraction & Activities & Clinical $\boldsymbol{E}$. coli isolate & Clinical $\boldsymbol{S}$. aureus isolate \\
\cline { 2 - 4 } & & Mean \pm SEM $(\mathrm{mg} / \mathrm{ml})$ & Mean \pm SEM $(\mathrm{mg} / \mathrm{ml})$ \\
\hline Methanol extract & MIC & $25.00 \pm 0.000$ & $12.50 \pm 0.000$ \\
\cline { 2 - 4 } & MBC & ND & ND \\
\hline Acetone extract & MIC & $25.00 \pm 0.000$ & $12.50 \pm 0.000$ \\
\cline { 2 - 4 } & MBC & ND & ND \\
\hline n-hexane fraction & MIC & $100.00 \pm 0.000$ & $100.00 \pm 0.000$ \\
\cline { 2 - 4 } & MBC & ND & ND \\
\hline Chloroform fraction & MIC & $100.00 \pm 0.000$ & $100.00 \pm 0.000$ \\
\cline { 2 - 4 } & MBC & ND & ND \\
\hline Ethyl acetate fraction & MIC & $6.250 \pm 0.000$ & $3.125 \pm 0.000$ \\
\cline { 2 - 4 } & MBC & $200.00 \pm 0.000$ & $83.33 \pm 16.667$ \\
\hline Aqueous fraction & MIC & $66.67 \pm 16.667$ & $25.00 \pm 0.000$ \\
\cline { 2 - 4 } & MBC & ND & ND
\end{tabular}


Mean value expressed as Mean \pm SEM $(n=3), N D=$ not detected

\section{Determination of minimum inhibitory and fungicidal concentration of crude extracts and solvent fractions of methanol extract against Candida albicans.}

The minimum fungistatic concentration of crude extracts and solvent fractions of methanol extract ranging from $3.125 \mathrm{mg} / \mathrm{ml}$ of the aqueous fraction to $66.67 \mathrm{mg} / \mathrm{ml}$ of methanol crude extract against $C$. albicans. The minimum fungicidal concentration of solvent fractions of methanol extract ranging from $50 \mathrm{mg} / \mathrm{ml}$ of the aqueous fraction to $200 \mathrm{mg} / \mathrm{ml}$ of ethyl acetate fraction. However, the minimum bactericidal concentration of methanol and acetone crude extracts were not detected against $C$. albicans (Table 10).

Table 10: MIC and MFC of crude extracts and solvent fractions against fungi.

\begin{tabular}{lll}
\hline Test extract and fraction & Activities & \multicolumn{1}{c}{ Candida albicans } \\
\cline { 2 - 3 } & & Mean \pm SEM $(\mathrm{mg} / \mathrm{ml})$ \\
\hline Methanol extract & MIC & $66.67 \pm 16.667$ \\
\cline { 2 - 3 } & MFC & ND \\
\hline Acetone extract & MIC & $41.67 \pm 8.333$ \\
\cline { 2 - 3 } & MFC & ND \\
\hline n-hexane fraction & MIC & ND \\
\cline { 2 - 3 } & MFC & ND \\
\hline Chloroform fraction & MIC & ND \\
\cline { 2 - 3 } & MFC & ND \\
\hline Ethyl acetate fraction & MIC & $16.67 \pm 4.167$ \\
\cline { 2 - 3 } & MFC & $200.00 \pm 0.000$ \\
\hline Aqueous fraction & MIC & $3.125 \pm 0.000$ \\
\cline { 2 - 3 } & MFC & $50.00 \pm 0.000$ \\
& &
\end{tabular}

Mean value expressed as Mean $\pm \operatorname{SEM}(n=3), N D,=$ not detected

Preliminary screening of phytochemical constituents of Ricinus communis Linn leaf

The results of preliminary phytochemical investigations of Ricinus communis Linn leaf crude extracts and solvent fractions is indicated on table11. The phytochemical screening indicated alkaloids, flavonoids, terpenoids, tannins, cardiac glycosides, steroids, anthraquinones, saponins, and phenols in crude methanol extract and ethyl acetate fraction of Ricinus communis Linn leaf (Table 11 and 12).

Table 11: Phytochemical constituents of crude extracts and solvent fractions of methanol extract of Ricinus communis Linn leaf. 


\begin{tabular}{|c|c|c|c|c|c|c|}
\hline \multirow[t]{2}{*}{ Secondary metabolites } & \multicolumn{2}{|c|}{ Crude extract } & \multicolumn{4}{|c|}{ Solvent fractions } \\
\hline & Methanol & Acetone & n-hexane & Chloroform & Ethyl acetate & Aqueous \\
\hline Flavonoids & + & + & - & + & + & + \\
\hline Alkaloids & + & + & + & + & + & + \\
\hline Saponins & + & - & - & + & + & + \\
\hline Cardiac glycosides & + & + & - & - & + & + \\
\hline Terpenoids & + & + & - & - & + & + \\
\hline Tannins & + & + & + & + & + & + \\
\hline Steroids & + & - & - & - & + & + \\
\hline Phenols & + & + & + & + & + & + \\
\hline Anthraquinones & + & - & - & - & + & - \\
\hline
\end{tabular}

-, absence, +, presence

\section{Discussion}

The current study aimed to investigate antimicrobial activities of crude extracts and solvent fractions of methanol extract of Ricinus communis Linn leaf against pathogenic bacteria and Candida albicans. However, antibacterial activity had been done by a previous study from Gonder, Ethiopia, but this study did not include antifungal activity and methanol solvent for extraction [16]. Furthermore, the previous findings have been reported that methanol solvent extract exhibited best antimicrobial activities from Ghana and Pakistan [14,15]. Both methanol and acetone crude extracts were also assessed for their antimicrobial activities to select the one which exhibited better antimicrobial activity for further solvent fractionation. There was a difference in the antimicrobial activities of the two extracts for presence and concentration of secondary metabolites could be affected by the type of solvent used for extraction [17].

The current study indicated that ethyl acetate fraction exhibited the highest antimicrobial activities in all tested microorganisms. Crude extracts were tested for their effects against gram-positive and gram-negative bacteria for their antimicrobial activities. Methanol crude extract revealed higher antimicrobial activity than acetone crude extract at the same concentrations. This finding agrees with that of the previous studies of Chandrasekaran and Venkatesalu [34], Naz and Bano [14], and Suurbaar et al. [15]. It is payable to the capability of methanol dissolving more secondary metabolites [34]. Methanol and acetone crude extracts exhibited greater antibacterial activities against gram-positive bacteria than gram-negative bacteria in a concentration-dependent manner. This could be because of differences in cell surface structure between gram-positive and negative bacteria. The outer membrane of gram-negative bacteria possesses lipopolysaccharides and lipoproteins. The lipopolysaccharides are amphipathic compounds that comprised hydrophilic polysaccharide at the core that makes up a more rigid outer membrane which slows down the diffusion of hydrophobic compounds through gram-negative bacteria cell membranes and acts as a barrier of permeability $[6,7,8]$. 
The solvent fractions of methanol extract exhibited antimicrobial activity in a concentration-dependent manner except for $n$-hexane fraction that showed no antibacterial activity against $P$. aeruginosa. Hexane and chloroform fractions revealed the lowest antibacterial activity and no antifungal activity. This could be due to variations in the concentration of secondary metabolites present in the solvent fractions [35,36]. Ethyl acetate fraction revealed highest antibacterial activity than crude extracts and solvent fractions which is in agreement with the finding of the previous study done by Voukeng et al. [19]. The aqueous fraction exhibited the highest antifungal activity followed by ethyl acetate fraction perhaps due to the capability of ethyl acetate solvent in concentrating a greater number of secondary metabolites from partitioning of methanol crude extract and interaction of these phytochemical constituents. Secondary metabolites with antifungal activity are concentrated more in aqueous solvent of methanol crude extract [35,36,37].

Mean of inhibition zone diameter of crude extracts and solvent fractions were significantly $(P<0.05)$ lower than the mean of inhibition zone diameter of positive control. The reason could be crude extracts and solvent fractions possessed both pharmacologically active and non-active substances whereas, control positive possessed purified and concentrated active ingredient [38]. Contrary to this, mean of inhibition zone diameter of crude methanol extract and aqueous fraction against $S$. pyogenes, crude acetone extract and chloroform fraction against $K$. pneumoniae, and ethyl acetate fraction against all tested gram-positive bacteria, $P$. aeruginosa and clinical $S$. aureus at $400 \mathrm{mg} / \mathrm{ml}$ displayed inhibition zone comparable to the positive control. Furthermore, the mean inhibition zone diameter of crude methanol extract, ethyl acetate fraction, and aqueous fraction against $K$. pneumoniae at $400 \mathrm{mg} / \mathrm{ml}$ was significantly $(\mathrm{P}<0.05)$ higher than the mean of inhibition zone diameter of positive control. Mean of inhibition zone diameter of crude extracts and solvent fractions against clinical isolate $E$. coli and $S$. aureus were slightly lower than that of laboratory strains $E$. coli and S. aureus which is in agreement with the finding of Molla et al. [39].The resistance mechanisms such as efflux pumps, $\beta$-lactamase production, and biofilm formation could have hindered the effectiveness of antibacterial in clinical isolates than laboratory strains $[40,41]$.

The broth microdilution technique revealed the lowest minimum inhibitory concentration for ethyl acetate fraction against pathogenic bacteria whereas, aqueous fraction against yeast. The experiment indicated that the minimum inhibitory concentration of the broth microdilution technique was inversely proportional to the inhibition zone of the agar well diffusion technique. This is an indication of the reproducibility of an experiment [42]. The ethyl acetate fraction also exhibited minimum bactericidal and fungicidal concentration against all tested microorganisms. Apart from this, $\mathrm{n}$-hexane and chloroform fractions were devoid of bactericidal and fungicidal activity. This could be due to the concentration of higher number secondary metabolites in ethyl acetate fraction than crude extract and solvent fractions despite the detection of phytochemical constituents [36,37].

The maceration technique was performed for the extraction of Ricinus communis Linn leaf and yielded a higher percent for methanol crude extract than acetone crude extract. The solvent fractionation yielded a higher percent for aqueous fraction than other solvent fractions. The phytochemical constituents screening revealed the presence of flavonoids, alkaloids, saponins, cardiac glycosides, terpenoids, tannins, steroids, phenols, and anthraquinones in methanol crude extract and ethyl acetate fraction whereas, anthraquinones were not detected in the aqueous fraction. Saponins, steroids, and anthraquinones were absent in acetone crude extract, but only alkaloids, tannins, and phenols were presented in n-hexane fraction. The capacity of methanol solvent in extracting more percent of extract yield and phytochemical constituents is in agreement with the findings of Felhi et al. [9] from Tunisia and Truong et al. [43] from Vietnam. The variation in types and concentration of phytochemical constituents and percent of extract yield is because of the difference in substance solubility among solvents. The difference in solubility of a substance might be based on the physical and chemical properties of solvents and phytochemical 
constituents. Types, quantity, and interactions of secondary metabolites present in crude extracts and solvent fractions are determinants of antimicrobial activities $[9,36,44,45]$. This study was conducted using small number of pathogenic bacteria and one fungal species which could be a limitation

\section{Conclusion}

The methanol extract of Ricinus communis Linn leaf constituted all screened secondary metabolites and exhibited the best antimicrobial properties against all tested microorganisms in a concentration-dependent manner. Among the solvent fractions from crude methanol extract, ethyl acetate fraction constituted all screened secondary metabolites and revealed the most pronounced antimicrobial activity than crude extracts and other solvent fractions, but aqueous fraction exhibited better anticandidal activity. The current study supports the claims of use of Ricinus communis Linn leaf as traditional medicine for the treatment of infectious diseases caused by bacterial and fungal pathogens. Further studies should be conducted on ethyl acetate fraction to isolate, purify, and identify bioactive principle(s) responsible for antibacterial and antifungal activities of the plant.

\section{List Of Abbreviations}

ANOVA, Analysis of Variance; ATCC, American Type Culture Collection; BHI, Brain Heart Infusion; CFU, Colony Forming Units; DMSO, Dimethyl Sulfoxide; MBC, Minimum Bactericidal Concentrations; MFC, Minimum Fungicidal Concentration; MHB, Muller Hinton Broth; MIC, Minimum Inhibitory Concentration; MHA, Muller Hinton Agar; CLSI, Clinical Laboratory Standard Institute; SEM, Standard Error of Mean; SPSS, Statistical Package for Social Sciences

\section{Declarations}

\section{Ethics approval and consent to participate}

Not applicable

\section{Consent for publication}

The study was approved by Ethics Review Board of School of Pharmacy in Addis Ababa University but no consent was needed.

\section{Availability of data and materials}

The datasets used and/or analysed during the current study are available from the corresponding author on reasonable request.

\section{Competing interests}

The authors declare that they have no competing interests.

\section{Funding}

This is described in acknowledgement.

\section{Authors' contributions}


BK developed proposal; designed and conducted all laboratory experiments; analyzed and interpreted experimental results; developed manuscript.WS supervised the study, and involved in proposal development and manuscript preparations. Authors read and approved the final manuscript.

\section{Acknowledgements}

The authors would like to acknowledge Addis Ababa University and Animal Products, Veterinary drug, Animal Feed Assessment Center of Ethiopian Veterinary Drug and Animal Feed Administration Control Authority for their sponsorship of the study. Animal Products, Veterinary drug, Animal Feed Assessment Center of Ethiopian Veterinary Drug and Animal Feed Administration Control Authority for accessing its laboratory facilities and provision of gentamicin. Ethiopian Biodiversity Institute and Ethiopian Public Health Institute for their provision of test microorganisms and sheep blood. Ethiopian Food and Drug Administration and Control Authority for provision of amphotericin-B.

\section{Authors' Information}

BT is (DVM, MSc) is pharmacologist and analyst at Animal Products, Veterinary drug, Animal Feed Assessment Center of Ethiopian Veterinary Drug and Animal Feed Administration Control Authority.

WS (DVM, MSC, PhD) is associate professor of pharmacology in the Department of Pharmacology and Clinical Pharmacy, School of Pharmacy, College of Health Sciences, Addis Ababa University

\section{References}

1. Rwego, I.B., Isabirye-Basuta, G., Gillespie, T.R., Goldberg, T.L. Gastrointestinal bacterial transmission among humans, mountain gorillas, and livestock in Bwindi Impenetrable National Park, Uganda. Conserv. Biol. 2008, 22(6):1600-1607.

2. Uchil, R.R., Kohli, G.S., Katekhaye, V.M., Swami, O.C. Strategies to Combat Antimicrobial Resistance. J. Clin. Diag. Res. 2014, 8(7): ME01-ME04.

3. Kerro, 0., Tareke, F. Bovine Mastitis in selected areas of southern Ethiopia. Tropical Animal health and production. 2003, 35:197-205.

4. Getahun, K., Kelay, B., Bekana, M., Lobago, F. Bovine mastitis and antibiotic resistance patterns in Selalle smallholder dairy farms, central Ethiopia. Trop. Anim. Health Prod. 2008, 40:261-268.

5. Bedasa S, Shiferaw D, Abraha A and Moges T. Occurrence and antimicrobial susceptibility profile of Escherichia coli 0157:H7 from food of animal origin in Bishoftu town, central Ethiopia. Inter.J.Food Cont. 2018, $5: 2$.

6. Helander, L.M., Alakomi, H.-L., Latva-Kala, K. et al. Characterization of the action of selected essential oil components on Gram-negative bacteria. J. Agri.Food Chem.1998, 46:3590-3595.

7. Puupponen-Pimia, R., Nohynek, L., Meier, C., Kahkonen, M., Heinonen, M. et al. Antimicrobial properties of phenolic compounds from berries. J. Appl. Microbiol. 2001, 90:494-507.

8. Zgurskaya, H.I., Löpez, C.A., Gnanakaran, S. Permeability Barrier of Gram-Negative Cell Envelopes and Approaches to Bypass It. ACS Infect. Dis.2015, 1(11): 512-522.

9. Felhi, S., Daoud, A., Hajlaoui, H., Mnafgui, K., Gharsallah, N., Kadri, A. Solvent extraction effects on phytochemical constituents' profiles, antioxidant and antimicrobial activities and functional group analysis of 
Ecballium elaterium seeds and peels fruits. Food Sci. Technol. Campinas. 2017, 37(3): 483-492.

10. Bayecha, F.B., Hordofa, D.L., Nurfeta, D.G., Abebe, R.A. Survey of Ethno-veterinary Medicinal Plants at Dale Sadi districts of Oromia Regional state, Western Ethiopia. J. Nat. Sci. Res. 2018, 8(19).

11. Mengesha, A., Dessie, D. Ethnoveterinary Medicine Knowledge and Practices in and around Gondar, Ethiopia. Inter.J. Publ.Health. Pharm.Pharma.2018, 3(1):39-68.

12. Gijan, M., Dalle, G. Ethnobotanical study of Medicinal plants in Nagelle Arsi district West Arsi Zone of Oromia, Ethiopia. J. Nat. Sci. Res. 2019, 9(13).

13. Romha, G., Dejene, T.A., Telila, L.B., Bekele, D.F. Ethnoveterinary medicinal plants: Preparation and application methods by traditional healers in selected districts of southern Ethiopia. Vet. World. 2015, 8(5):674-684.

14. Naz, R., Bano, A. Antimicrobial potential of Ricinus communis leaf extracts in different solvents against pathogenic bacterial and fungal strains. Asian Pac. J. Trop. Biomed. 2012, 2(12): 944-947.

15. Suurbaar, J., Mosobil, R., Donor, A.M. Antibacterial and antifungal activities and phytochemical profile of leaf extract from different extractants of Ricinus communis against selected pathogens. BMC Res. Notes.2017, 10:660.

16. Abew, B., Sahile, S., Moges, F. In vitro antibacterial activity of leaf extracts of Zehneria scabra and Ricinus communis against Escherichia coli and methicillin resistance Staphylococcus aureus. Asian Pac. J. Trop. Biomed. 2014, 4(10): 816-820.

17. Liu, W., Yin, D., Li, N., Hour, X., Wang, D., et al. Influence of environmental factors on the active substance production and antioxidant activity in Potentilla fruticosa L. and its quality assessment. Scientific Reports. 2016.

18. Ogbiko, C., Eboka, C.J., Tambuwal, A.D. Extraction and Fractionation of Whole Black Seed Plantain (Plantago rugelii Decne) for in-vitro Antioxidant, Antibacterial and Phytochemical Screening. J. Appl. Sci. Environ. Manage. 2018, 22 (5):613- 618.

19. Voukeng, I.K., Nganou, B.K., Sandjo, L.P., Celik, I., Bing, V.P. Antibacterial activities of the methanol extract, fractions and compounds from Elaeophorbia drupifera (Thonn.) Stapf. (Euphorbiaceae). BMC Compl. Alter. Med.2017,17:28.

20. Ayoola, G.A., Coker, H.A.B., Adesegun, S.A, Adepoju-Bello, A.A., Obaweya, et al. Phytochemical Screening and Antioxidant Activities of Some Selected Medicinal Plants Used for Malaria Therapy in Southwestern Nigeria. Trop.J. Pharma.Res.2008, 7 (3): 1019-1024.

21. Nwadiaro, P.O., Ogbonna, A.I., Wuyep, P.A. Sila-Gyang, M.D. Antifungal Activity of Cucumis metuliferus E. Mey. ex Naudin on Some Post-harvest Decay Fungi of String beans. J.Acid.Indus.Res. 2015, 3:10.

22. Shetty, S.B., M. ahin-Syed-Ismail, P., Varghese, S., Thomas-George, B., Kandathil-Thajuraj, P. et al. Antimicrobial effects of Citrus sinensis peel extracts against dental caries bacteria: An in vitro study. J. Clin. Exp. Dent. 2016, 8(1): e71-7.

23. Santhi, K., Sengottuvel, R. (2016). Qualitative and Quantitative Phytochemical analysis of Moringa concanensis Nimmo. Int.J.Curr.Microbiol.App.Sci.2016, 5(1): 633-640.

24. Clinical and Laboratory Standard Institute. Abbreviated Identification of Bacteria and Yeast. Approved guideline $2^{\text {nd }}$ edn. 2008. CLSI document M35-A2. Wayne, PA: CLSI.

25. Brown, V.I., Lowbury, E.J.L. Use of an improved cetrimide agar medium and of culture methods for Pseudomonas aeruginosa J. Clin. Pathol. 1965, 18: 752. 
26. Clinical and Laboratory Standard Institute. Methods for dilution Antimicrobial susceptibility tests for bacteria that grow aerobically; Approved Standard 10 ${ }^{\text {th }}$ edn. 2015. CLSI document M07-A10. Wayne, PA: CLSI.

27. Umer, S., Tekewe, A., Kebede, N. Antidiarrhoeal and antimicrobial activity of Calpurnia aurea leaf extract. BMC Compl.Alt.Med.2013, 13:21.

28. Gonelimali, F.D., Lin, J., Mao, W., Xuan, J., Charles, F., et al. Antimicrobial Properties and Mechanism of Action of Some Plant Extracts Against Food Pathogens and Spoilage Microorganisms. Front. Microbiol. 2018, 9:1639.

29. Ohikhena, F.U., Wintola, O.A., Afolayan, A.J. Evaluation of the Antibacterial and Antifungal Properties of Phragmanthera capitata (Sprengel) Balle (Loranthaceae), a Mistletoe Growing on Rubber Tree, Using the Dilution Techniques. Hindawi. Sci. World J. 2017, Article ID 9658598.

30. European Committee for Antimicrobial Susceptibility testing (EUCAST). Method for the determination of. Minimum inhibitory concentration (MIC) by broth dilution of fermentative yeasts. Subcommittee on Antifungal susceptibility testing (AFST) of the ESCMID. E.Dis.7.1. Cli.Microbiol.Inf.2003,9:8.

31. Taye, B., Giday, G., Animus, A., Seid, J. Antibacterial activities of selected medicinal plants in traditional treatment of human wounds in Ethiopia. Asian Pac. J. Trope. Boomed. 2011, 2: 370-375.

32. Blaži'c, M., Balaž, A.M., Prodanovi'c, O., Popovi'c, N., Ostafe, R. Directed Evolution of Cellobiose Dehydrogenase on the Surface of Yeast Cells Using Resazurin-Based Fluorescent Assay. Appl. Sci. 2019, 9:1413.

33. Akinduti, P.A., Motayo, B., Idowu, O.M., Isibor, P.O., Olasehinde, G.I., et al. Suitability of spectrophotometric assay for determination of honey microbial inhibition. J. Phys.: 2019, Conf. Ser. 1299012131.

34. Chandrasekaran, M., Venkatesalu, V. Antibacterial and antifungal activity of Syzygium jambolanum seeds. J. Ethnopharmacol. 2004, 91:105-108.

35. Osuagwu, G.G.E., Emi, C.F. The Phytochemical Composition and Antimicrobial Activity of Dialium Guineense, Vitex Doniana and Dennettia Tripetala Leaves. Asian J.Nat.Appl. Sci.2013, 2:3.

36. Palmer-Young, E.C., Sad, B.M., Irwin R.E., Adler, L.S. Synergistic effects of floral phytochemicals against a bumble bee parasite. Wiley Eco.Evol.2017,7:1836-1849.

37. Sisay, M., Bussa, N., Gashaw, T., Mengistu, G. Investigating In Vitro Antibacterial Activities of Medicinal Plants Having Folkloric Repute in Ethiopian Traditional Medicine. J. Evidence-Based Integrative Med. 2019, $24:$ 1-9.

38. Ezekiel, C.N., Anokwuru, C.P., Nsofor, E., Odusanya, O.A., Adebanjo, O. Antimicrobial Activity of the Metabolic and crude Alkaloid Extracts of Acalpha wilkesiana cv. Macafeeana copper leaf. Res. J. Microbiol.2009, 4(7):269-277.

39. Molla, Y., Nedi, T., Tadesse, G., Alemayehu, H., Shibeshi, W. Evaluation of the in vitro antibacterial activity of the solvent fractions of the leaves of Rhamnus prinoides L'Herit (Rhamnaceae) against pathogenic bacteria. BMC Compl.Alter.Med.2016, 16:287.

40. Patel, J.B., and Richter, S.S. Mechanisms of resistance to antibacterial agents. Antibacterial agents and susceptibility test methods. Manual of Clinical Microbiology. $11^{\text {th }}$ edn.2015. ASM Press. Texas, USA.

41. Kapoor, G., Saigal, S., and Elongavan, A. Action and Resistance Mechanisms of Antibiotics. A guide for clinicians. J. Aneasthesiol. Clin. Pharmacol. 2017, 33:300-305.

42. Scorzoni, L., Benaducci, T., Almeida, A.M.F., Silva, D.H.S., Bolzani, V.S., Mendes-Ginning, M.J.S. Comparative study of disk diffusion and microdilution methods for evaluation of antifungal activity of natural compounds against medical yeasts Candida spp. and Cryptococcus spp. J. Basic Apple. Pharma. Sci.2007, 28: 25-34. 
43. Truong, DH., Nguyen, D.H., Ta, N.T.A., Bui, A.V., Do, T.H., Nguyen H.C. Evaluation of the Use of Different Solvents for Phytochemical Constituents, Antioxidants, and In Vitro Anti-Inflammatory Activities of Severinia buxifolia. Hindawi J. Food Quality.2019, Art. ID 8178294.

44. Cowan, M. Plant products as antimicrobial agents. Clin. Microbial. Rev. 1999, 12:564-582.

45. Shafique, S., Bajwa, R., Akhtar, N., Hanif, S. Fungitoxic activity of aqueous and organic solvent extracts of Tagetes erectus on phytopathogenic fungus Ascochyta rabiei. Pak. J. Bot. 2011, 43: 59-64. 